\title{
Visible-Light-Sensitive Photopolymer Systems Using Diol Monosulfonate as Acid Amplifiers
}

\author{
Akira Teranishi, Koji Arimitsu, Shin'ya Morino, Soh Noguchi, and Kunihiro Ichimura
}

Research Laboratory of Resources Utilization, Tokyo Institute of Technology, 4259 Nagatsuta, Midori-ku, Yokohama 226-8503, Japan

Keywords: acid proliferation, visible light, sensitizer dye, diol monosulfonate, acid amplifier

We have proposed a new concept of acid proliferation reactions which involves the acid-catalyzed decomposition of an organic compound to release another strong acid, leading to the autocatalytic decomposition. On the bases of this concept, we have so far studied on photoresist materials using these acid amplifiers for UV light sensitive systems to improve this photosensitivity.[1-5] Chemically amplified photoresists for visible laser direct imaging were reported.[6,7] This material consists of a photoacid generator, a sensitizer dye and an acidlabile polymer. In this system, the formation of acid from a photoacid generator sensitized by a dye results in the acid-catalyzed deprotection of acid-labile polymer, providing positive-working photoresists.

In this work, we adopt this system and aimed at the development a novel visible-light-sensitive photopolymer using acid amplifiers to improve the photosensitivity ( Fig. 1 ).

A film of poly(tert-butyl methacrylate) (PTBMA) containing $10 \mathrm{wt} \%$ of diphenyliodonium triflate (DPITf) as a photoacid generator, $2 \mathrm{wt} \%$ of 9,10-bis(phenylethynyl)anthracene (BPEA) or 1,8-dimethoxy-9,10-bis(phenylethynyl)anthracene as a sensitizer dye and $10-20 \mathrm{wt} \%$ of cis-3-(ptoluenesulfonyloxy)-2-pinanol (1) as an acid amplifier was made by spin-coating onto a silicon wafer and baking at $110^{\circ} \mathrm{C}$ on a

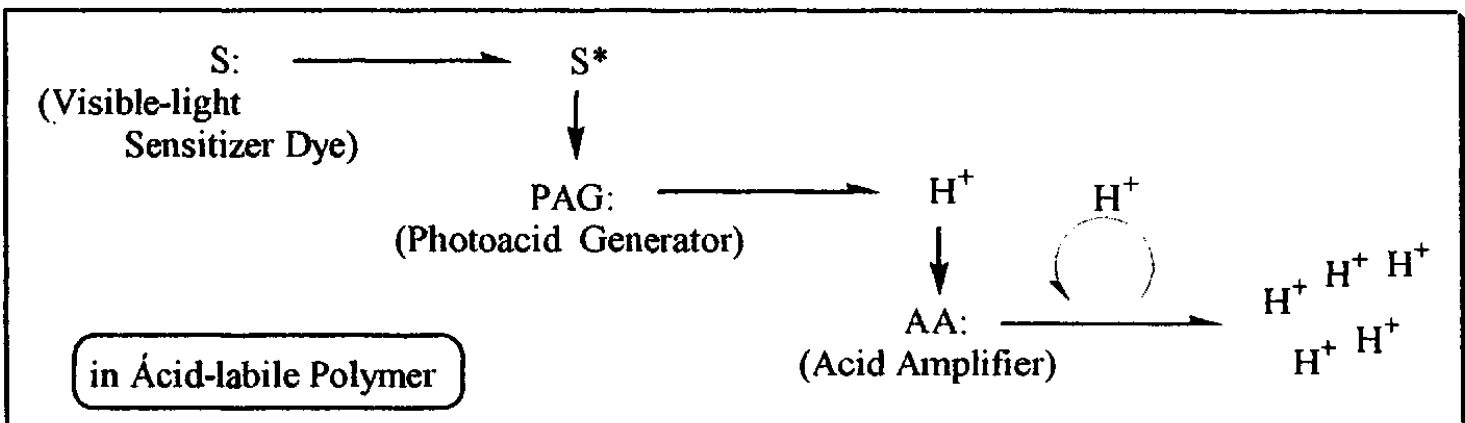

Fig. 1. Visible-light-sensitive photopolymer system 


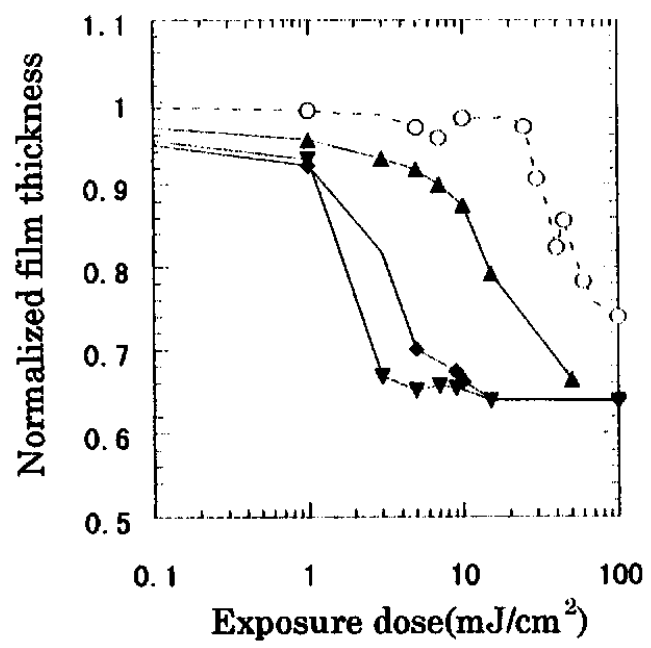

Fig. 2 Sensitivity curves of PTBMA films containing $10 \mathrm{wt} \%$ DPI'T and $2 \mathrm{wt} \%$ BPEA in the absence of $(\mathrm{O})$ and in the presence of $10 \mathrm{wt} \%(\Delta), 15 \mathrm{wt} \%(\Delta)$ and 20 wt $\%$ of $1(\nabla)$ upon $436 \mathrm{~nm}$ irradiation.

hot stage to give a film of 2.5-3.0 $\mu \mathrm{m}$ in thickness. The films were exposed subsequently to $436 \mathrm{~nm}$ light using a $\mathbf{H g}-\mathrm{Xe}$ lamp or $\mathbf{4 8 8} \mathrm{nm}$ light using an Ar laser, followed by heating at $110{ }^{\circ} \mathrm{C}$ for 90 sec to give rise to the acid-catalyzed reaction. The film thickness was measured to give phtosensitivity characteristics.

Fig. 2 shows photosensitivity characteristics of the photopolymer systems. The new materials containing the acid amplifier have high photosensitivity when compared to the material in the absence of the acid amplifier. Furthermore the sensitivity and the contrast became higher as the concentration of 1 was increased.
These results indicate that photogenerated acidic species from DPITf initiate the decomposition of the acid amplifier, leading to the proliferation of acidic species, followed by the acid-catalyzed deprotection of PTBMA.

In summary, we developed new visible-lightsensitive photopolymer systems using an acid amplifier. These materials show high photosensitivity, due to the proliferation of acidic species generated from the acid amplifier.

\section{References}

1 K. Ichimura, K. Arimitsu, K. Kudo, Chem. Lett., 551 (1995).

2 K. Arimitsu, K. Kudo, K. Ichimura, $J$ Am. Chem. Soc., 120, 37 (1998).

3 K. Kudo, K. Arimitsu, H. Ohmori, K. lchimura, J. Photopolym. Sci. Technol., 8, 45 (1995).

4 K. Arimitsu, S. Noguchi, K. Ichimura, $J$. Photopolym. Sci. Technol., 10, 313 (1997).

5 S. Noguchi, K. Arimitsu, K. Ichimura, K. Kudo, T. Ohfuji, M. Sasago, J. Photopolym. Sci. Technol., 10, 315 (1997).

6 G. M. Wallraff, R. D. Allen, W. D. Hinsberg, C. G. Willson, J. Imaging Sci. Technol., 36, 468 (1992).

7 Y. Ohe, K. Ichimura, Polym. Adv. Technol., 3, 9 (1992). 